\title{
Comparison of D-region Doppler drift winds measured by the SuperDARN Finland HF radar over an annual cycle using the Kiruna VHF meteor radar
}

\author{
N. F. Arnold ${ }^{1}$, P. A. Cook ${ }^{1,3}$, T. R. Robinson ${ }^{1}$, M. Lester ${ }^{1}$, P. J. Chapman ${ }^{1,4}$, and N. Mitchell ${ }^{2}$ \\ ${ }^{1}$ Department of Physics and Astronomy, University of Leicester, University Road, Leicester, LE1 7RH, UK \\ ${ }^{2}$ Department of Physics, University of Wales, Aberystwyth, Ceredigion, SY23 3BZ, UK \\ ${ }^{3}$ now at: The Department of Physics, Imperial College, Prince Consort Road, London, UK \\ ${ }^{4}$ now at: The Department of Communication Systems, Lancaster University, Lancaster, LA1 4YR, UK
}

Received: 6 September 2001 - Revised: 15 January 2003 - Accepted: 7 February 2003

\begin{abstract}
The SuperDARN chain of oblique HF radars has provided an opportunity to generate a unique climatology of horizontal winds near the mesopause at a number of high latitude locations, via the Doppler shifted echoes from sources of ionisation in the D-region. Ablating meteor trails form the bulk of these targets, but other phenomena also contribute to the observations. Due to the poor vertical resolution of the radars, care must be taken to reduce possible biases from sporadic-E layers and Polar Mesospheric Summer echoes that can affect the effective altitude of the geophysical parameters being observed. Second, there is strong theoretical and observational evidence to suggest that the radars are picking up echoes from the backward looking direction that will tend to reduce the measured wind strengths. The effect is strongly frequency dependent, resulting in a $20 \%$ reduction at $12 \mathrm{MHz}$ and a $50 \%$ reduction at $10 \mathrm{MHz}$.

A comparison of the climatologies observed by the SuperDARN Finland radar between September 1999 and September 2000 and that obtained from the adjacent VHF meteor radar located at Kiruna is also presented. The agreement between the two instruments was very good. Extending the analysis to the SuperDARN Iceland East radar indicated that the principles outlined above could be applied successfully to the rest of the SuperDARN network.
\end{abstract}

Key words. Ionosphere (ionosphere-atmosphere interactions; instruments and techniques) - Meteorology and atmospheric dynamics (waves and tides)

\section{Introduction}

The upper mesosphere and lower thermosphere region provides a natural demarcation between the essentially neutrally charged lower atmosphere and the strongly plasma influenced upper atmosphere (see, for example, Rees, 1989). Limitations in computing power traditionally confined climate models to the troposphere and occasionally the lower

Correspondence to: N. F. Arnold (nfa1@ion.le.ac.uk) stratosphere (see, for example, Peixoto and Oort, 1992). However, the extensive inter-connectivity of the atmosphere has led to the development of models that include the stratosphere and mesosphere up to $95 \mathrm{~km}$ (Fels et al., 1980; Gray et al., 1992). A natural continuation of this trend is to consider the dynamical impact of the lower thermosphere on the atmosphere below and vice versa.

It has been suggested that solar-induced changes in the thermosphere may bring about significant modifications to the circulation of the stratosphere via wave transport processes (Arnold and Robinson, 1998, 2000). Much of the large-scale observational information on winds in the upper mesosphere and lower thermosphere has come from two instruments on the Upper Atmosphere Research Satellite (McLandress et al., 1996; Fleming et al., 1996). Their geographical coverage was restricted to a maximum of $75^{\circ}$ north and south of the equator. Satellites can only take a couple of samples per day at any location and if the satellite precesses in orbit these measurements will have different local times. High levels of natural variability from tides, planetary waves, gravity waves and turbulence, in addition to experimental error, placed constraints on the quality of the data.

There have been many studies of the winds in the upper mesosphere and lower thermosphere by individual radars (see, for example, Röttger and Vincent, 1996 for a review). Combining these observations can produce difficulties because of the large differences between the observational techniques being employed. The Super Dual Auroral Radar Network (SuperDARN) was constructed and operated to measure large-scale ionospheric convection flows at high latitudes (Greenwald et al., 1995). Hall et al. (1997) recognised that at $\mathrm{HF}$ frequencies, these radars were also very effective at measuring meteor echoes. The Doppler shifts from meteor trails have long been used to infer the neutral winds in the upper atmosphere (Greenhow, 1952; Robertson et al., 1953; Greenhow and Neufeld, 1955). Hussey et al. (2000) demonstrated that the SuperDARN chain of HF radars provides a valuable facility to observe the evolution of large-scale dynamical processes over both short and long periods of time 

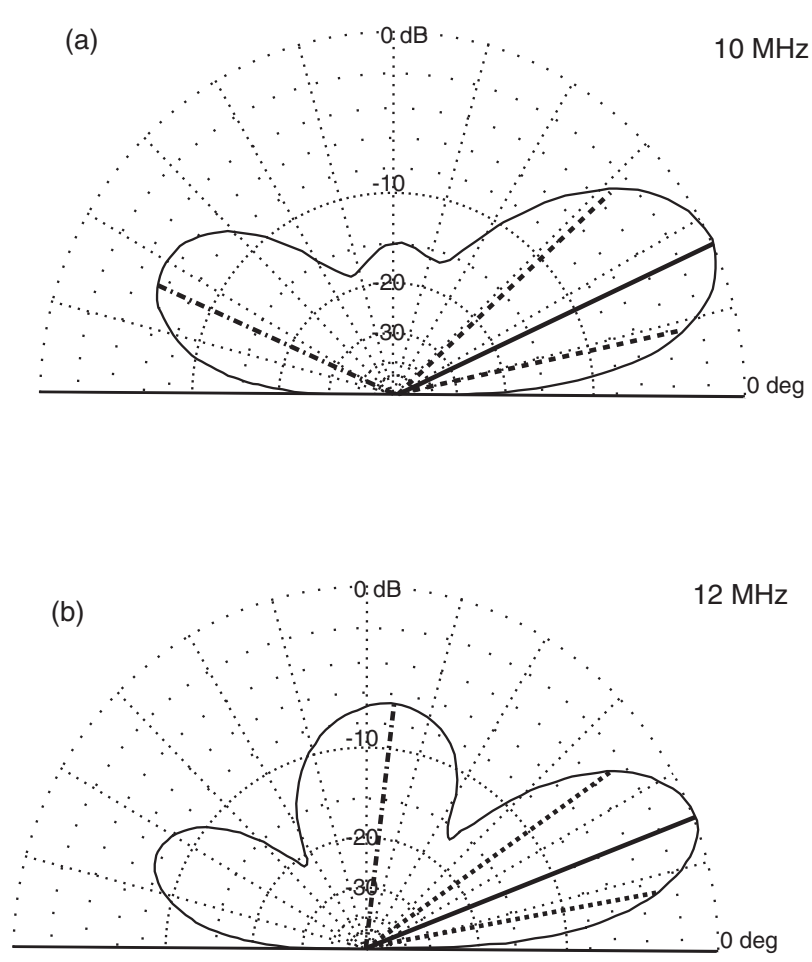

Fig. 1. SuperDARN Gain-Elevation plots for (a) $10 \mathrm{MHz}$ and (b) $12 \mathrm{MHz}$ (transmit only). The maximum sensitivities are at 26 and 22 degrees, respectively, and are denoted by thick solid lines. The angles of the $3 \mathrm{db}$ gain reductions are denoted by dashed lines and the largest side lobe by a dashed - dotted line.

in the upper mesosphere and lower thermosphere.

Most purpose-built meteor radars operate at frequencies above $30 \mathrm{MHz}$ (see, for example, Hocking, 1997) to minimise contamination from other ionospheric sources and ground-scatter. The approach adopted by Hall et al. (1997) for observations with the HF radars was to reject echo returns from beyond the fifth range gate $(360 \mathrm{~km}$ from the radar) and a Doppler velocity greater than $\pm 200 \mathrm{~ms}^{-1}$. The spectral width parameter was found to be related to the ambipolar diffusion which is itself strongly related to atmospheric temperature, pressure and the neutral-ion collision frequency (see, for example, Arnold et al., 2001). This criterion provided qualitatively reasonable results. However, there are occasions when more rigorous criteria need to be applied.

Not all radar echoes that fall within the criteria adopted by Hall et al. are in fact meteors. Recent work by Ogawa et al. (2002) and Kelley et al. (2002) has strongly suggested that the first few range gates of the HF radars are capable of detecting Polar Mesospheric Summer Echoes. These instabilities have low spectral widths and occur within the meteor layer. However, ions and electrons in this region are closely coupled to the neutral gas and so they will allow for a determination of the neutral winds to be made in the same way as the meteors, albeit with different echo characteristics.

In this paper, we shall present examples of systematic biases within the SuperDARN radars and ionospheric contam- ination of the returns that need to be taken into account. The deployment of a dedicated VHF meteor radar close to the Finland element of this network allowed for a detailed intercomparison to be conducted over a full year and demonstrated that with the appropriate level of quality control, good agreement between the two systems could be obtained. Further improvements to the D-region observing capability related to new hardware developments with the CUTLASS pair of SuperDARN radars will be discussed at the end of the paper.

\section{Description of the radar systems}

The CUTLASS pair of radars used in this study form part of the SuperDARN chain. The CUTLASS HF radars consist of 16 identical antennae and 4 interferometers with transmit/receive capability between $8-20 \mathrm{MHz}$ (see, for example, Milan et al., 1997). The Finland radar at Hankasalmi has been operational since February 1995, while the one at Pykkvibaer in Iceland commenced in November of the same year. Each beam is approximately 3 degrees wide and can be made to point to 16 adjacent volumes of space through electronic changes to the phasing. A typical scan will sweep through these elements, integrating the return signal from $30 \mathrm{~ms}$ pulse sequences over a period of 3 , or more normally, $7 \mathrm{~s}$. Real time processing of the incoming signals allows for the retrieval of the return power Doppler shifted velocity and spectral width, along with other parameters, such as the elevation angle of the echo. The data are ascribed to 75 range gates with a resolution of 15,30 or $45 \mathrm{~km}$, and the distance to the first range can also be varied according to the nature of the experiment. The "common programme" mode, which accounted for at least half of the days each month, has a first range of $180 \mathrm{~km}$ and a resolution of $45 \mathrm{~km}$.

The gain sensitivities of the radar transmitters as a function of elevation angle at $10 \mathrm{MHz}$ and $12 \mathrm{MHz}$ have been modelled (Fig. 1). The transmit and receive patterns are identical, so the total power variation in decibels is obtained by doubling the values plotted. The forward looking direction of the transmitters is on the right-hand side of the plots. The optimum angle at $10 \mathrm{MHz}$ was calculated to be around $26 \mathrm{de}-$ grees. Observed meteor echo strengths could exceed $30 \mathrm{~dB}$ above the "noise" threshold, so returns were to be expected over a wide range of viewing angles. In principle, meteors could be detected from vertical incidence at $10 \mathrm{MHz}$ and particularly at $12 \mathrm{MHz}$, but with a first range of $180 \mathrm{~km}$, these meteors will not be retrieved in the standard mode of operation.

There is a prominent backward lobe at $10 \mathrm{MHz}$, which is weaker at $12 \mathrm{MHz}$. As the take-off angle is comparable to the forward lobe, there is no simple way of discriminating between the two directions, for example, by comparing the elevation angles from the interferometer. A bright meteor travelling south from the reverse lobe will be indistinguishable from a weaker meteor travelling north from the forward looking direction. Evidence for scatter in the data via the rear 


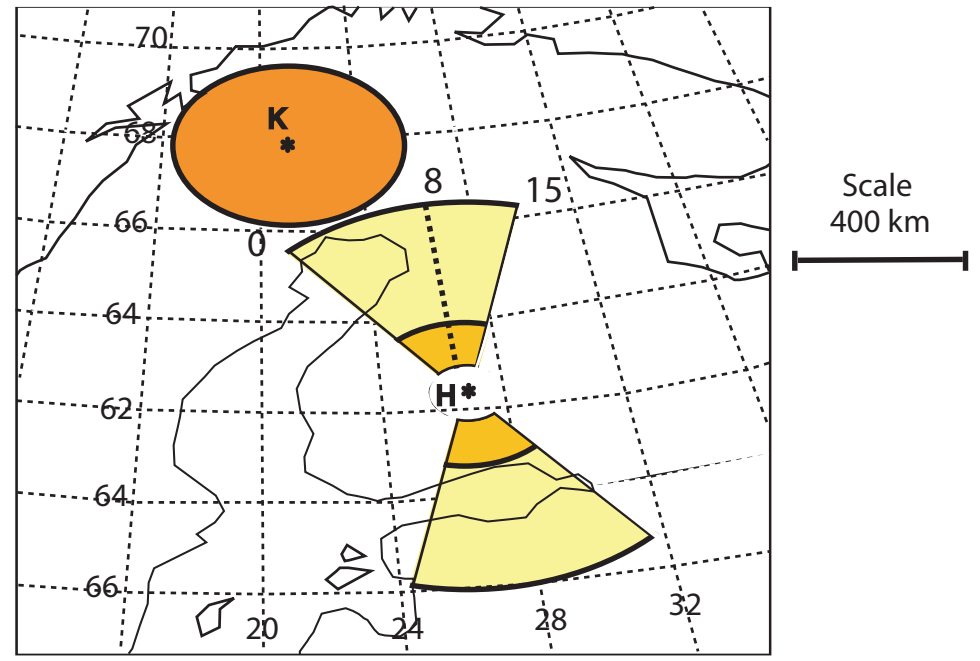

K - Kiruna
H - Hankasalmi
Fig. 2. Map of Northern Scandinavia with the locations of the Esrange VHF and SuperDARN Finland radars denoted by a $\mathrm{K}$ and an $\mathrm{H}$, respectively. The effective areas of meteor coverage are shaded. At Hankasalmi, the outer shaded regions are observed by the common scanning mode, while both the inner and outer shaded regions are covered by a dedicated high resolution meteor mode. lobe has been presented by Milan et al. (1997). A solution to this difficulty will be discussed later in the paper. D-region echoes can only appear in the vertical lobe when the first range gate has been shortened to less than $100 \mathrm{~km}$. Under these circumstances, two distinct populations will be formed by their differing geometries. E-region contamination from this mode will be kept to a minimum by a number of factors. The reduction in the gain sensitivity at the zenith at $10 \mathrm{MHz}$ is $30 \mathrm{~dB}$ (transmit and receive), but is much lower at $12 \mathrm{MHz}$ $(12 \mathrm{~dB})$. Ionospheric scatter from diffuse irregularities tend not to be as intense as meteor trails, so most echoes will be below the noise threshold of the radar. Also, most ionospheric echoes in the F-layer tend to have spectral widths that greatly exceed $50 \mathrm{~ms}^{-1}$. Finally, a significant fraction of the F-region ionospheric returns congregate in patches that have coherent temporal and spatial structure that can be identified by the processing software and will be discussed in the next section.

The interferometer is accurate to a few degrees only, so in combination with a range gate of $15 \mathrm{~km}$, it cannot be used to determine the altitude of the meteor echoes to better than approximately $10 \mathrm{~km}$. This is sufficient, however, to assess the extent to which the data is coming from the D- or the E-region. An intercomparison with the Saskatoon MF radar indicated that the average height was around $95 \mathrm{~km}$ (Hall et al., 1997). Using the range gate and the interferometer, estimates of velocity at $3-\mathrm{km}$ height intervals were provided, but the effective resolution was still 10-15 km (Hussey et al., 2000). Hall et al. (1997) first suggested the use of spectral width information to estimate the mean height of the measurements, as this quantity is related to the ambipolar diffusion rate of the meteor trail. Arnold et al. (2001) demonstrated that the spectral width parameter provided considerable information about the response of the meteor layer to changing atmospheric conditions. Higher horizontal reso- lution in the range gates from 45 to $15 \mathrm{~km}$ should improve matters during special meteor observing campaigns, but the number of days when the radars could operate in this mode would be limited to only a few days per month (Hussey et al., 2000).

At HF wavelengths, it is technically very difficult to construct a narrow beam that illuminates a small volume of the sky. As the SuperDARN radars operate over a range of frequencies, complex beam patterns are generated, especially away from the optimum operating frequency. Most of the radars operate at $12 \mathrm{MHz}$, but to improve the number of ionospheric returns, the CUTLASS radars have often used $10 \mathrm{MHz}$.

The VHF meteor radar at the Esrange rocket range in Kiruna, Sweden, was deployed in the summer of 1999 and a nearly continuous data set has been generated since August of that year to the present, with only a few significant gaps at the beginning of its operation. It consists of a single dipoletype transmitter with nearly uniform all-sky sensitivity and 5 receiver antennae. The radar operates at a frequency of $32.5 \mathrm{MHz}$. At this frequency the all-radio waves will travel through the lower ionosphere in an essentially straight line and only return to the radar if they encounter a suitable target. At further meteor ranges ground-backscatter following reflection from the E-layer can be a factor at lower HF frequencies. The all-sky beam pattern relies on interferometry to determine the azimuth, elevation and altitude of the echoes. The elevation angle can be measured to within $1-2^{\circ}$ (Hocking 1999) and in conjunction with a suitable gating of the incoming signal translates to a vertical resolution better than $2 \mathrm{~km}$, which is considerably better than that which is possible with the oblique HF radars. The effective fields-ofview of the Esrange and Finland radars were separated by a hundred kilometres (Fig. 2), but this will be shown to be sufficiently small enough to allow for the gross features in the 


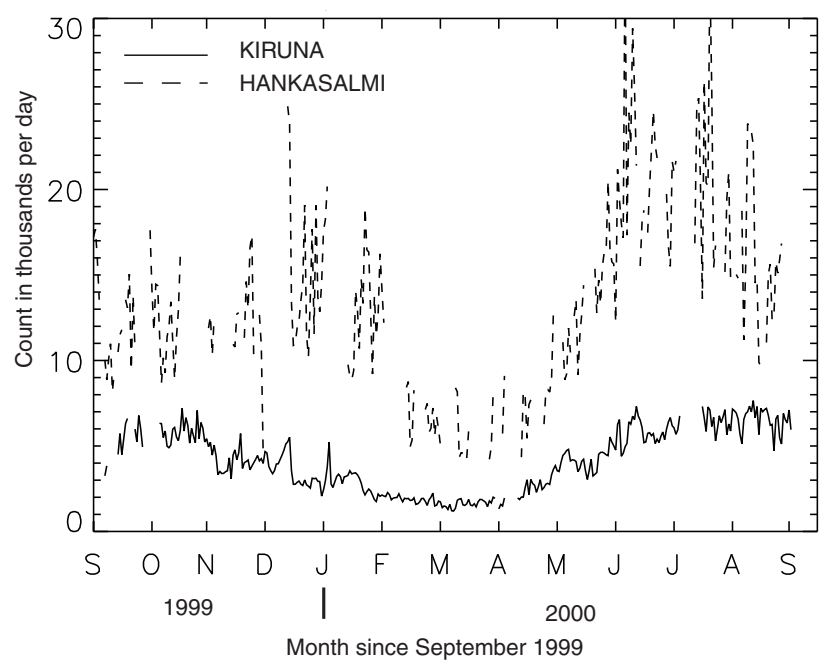

Fig. 3. Daily meteor count rates for the Hankasalmi HF radar (dashed lines) and the Kiruna VHF radar (solid lines).

upper atmosphere winds to be compared.

Only the first six range gates of the HF radar are being evaluated at present, as contamination from ionospheric scatter increases significantly with range, so there are no overlapping observations. Although the area illuminated by the CUTLASS radar is smaller, the higher sensitivity of the latter system and the increase in echoes at lower frequencies (see, for example, McKinley, 1961) result in significantly higher returns (Fig. 3) for the HF radar. One important source of echoes will be targets that have been incorrectly identified as meteors but have other ionospheric origins. There was a noticeable increase in the number of echoes from the CUTLASS radar part way through the study interval. This transition is due to the implementation of a 3-s integration time for approximately $30 \%$ of the Common Time operations. When the density of meteor returns was relatively large, multiple echoes could occur within an integration period and so a proportion of these could now be isolated; also the sampling rate was higher.

\section{Treatment of non-meteor data in the nearest range gates}

The operating frequencies of the CUTLASS Finland radar during common programme operations in 1999 and 2000 were chosen to be $12 \mathrm{MHz}$ between 06:00 and 18:00 UT and $10 \mathrm{MHz}$ at all other times, to detect the greatest number of ionospheric echoes. The nearest six ranges were cluttered with returns from many different sources. Often these have either broad spectral widths or large velocities or both, and provide a straightforward criterion for rejecting non-meteor data. Ionospheric echoes of non-meteor origins can have spectral widths of up to $1000 \mathrm{~ms}^{-1}$. In Arnold et al. (2001) the limits were set at $\pm 50 \mathrm{~ms}^{-1}$ for the line-of-sight velocities and $50 \mathrm{~ms}^{-1}$ for the spectral width. However, there re- (a)

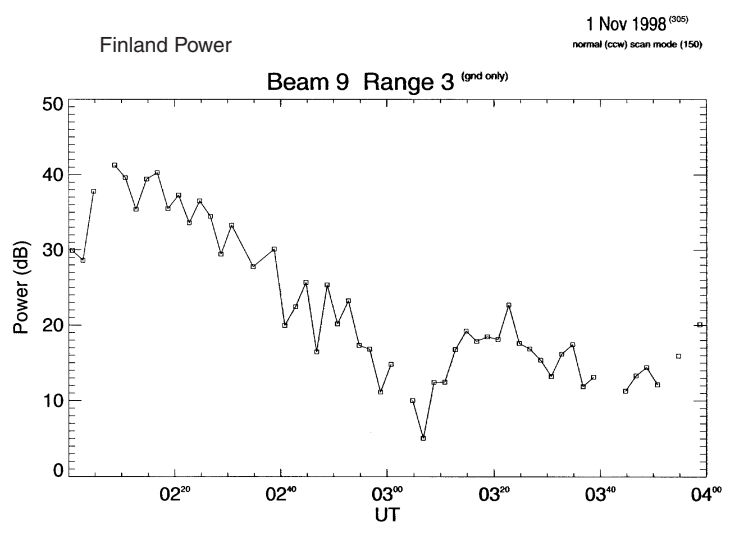

(b)

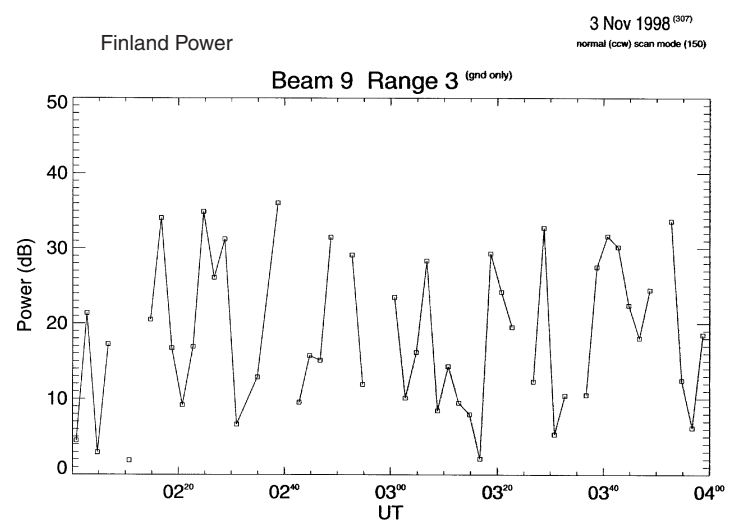

Fig. 4. Variations in SuperDARN Finland power returns from beam 9, range gate 3 flagged as "ground scatter" between 02:00-04:00 UT (a) 1 November 1998 (b) 3 November 1998.

main instances when non-meteor ionospheric scatter could be mistaken for meteor trails.

Sporadic-E echoes are intermittent, narrow reflection layers that are formed around $95-120 \mathrm{~km}$ by wind shears and other turbulent processes (e.g. Smith, 1978). Outside the auroral oval, they are predominantly summer phenomena and are especially prevalent in the daytime. During intense geomagnetic activity, sporadic-E can be seen at night due to increased precipitation of electrons from the solar wind (see, for example, Weber et al., 1977).

The ionised layer consists of metal ions that have originated from meteor ablation and drifted upwards (for a review, see Kopp, 1997). As the radar targets are layers rather than free moving ions, they naturally have low velocities and narrow spectral widths. Local time variations of returned power from a single beam and range gate on two separate days in early November illustrate the difference between the meteor (Fig. 4a) and sporadic-E (Fig. 4b) echoes, respectively. In contrast to the grainy, quasi-random distribution of location and power of the meteors described by Hall et al. (1997), sporadic-E returns tend to be highly coherent over a long period of time, in addition to taking up a large area (up to hundreds of kilometres) and being of considerable signal strength. There will be meteor echoes present in the sporadic 
layer data that may account for some of the variability in the signal power. A detailed analysis of the raw autocorrelation functions would be needed for any attempt to extract the superimposed meteor information and this is beyond the scope of this study.

Sometimes, sporadic-E occupies the entire field of view over many hours, in which case it is relatively easy to identify and reject the data automatically. However, more typically, there is only partial coverage - usually at the further ranges, while there are potentially useable meteor echoes at the nearer ranges. More elaborate retrieval algorithms would be needed to handle these situations. For the purposes of this paper, we have adopted a simple statistical approach. Where the mean power of returned echoes in a particular hour exceeded a particular threshold, that hour was rejected. An examination of mean back-scattered power as a function of local time and season indicated that any hourly data that exceeded a threshold of $24 \mathrm{~dB}$ was likely to be contaminated. Further refinement of the procedure could take account of the orientation of the Earth with respect to the trajectory of incoming meteors. This results in a strong diurnal cycle in back-scatter power, so it should be possible to generate a threshold that takes account of temporal variations in meteor strength.

In addition to backscatter power filtering, it is possible to discriminate between different echo generation mechanisms by considering the spectral width profile. This parameter is closely related to the ambipolar diffusion rate (Hall et al., 1997; Arnold et al., 2001) and within the meteor layer should have mean values of between $10-25 \mathrm{~ms}^{-1}$. However, E-region irregularities can also exhibit a spectral width distribution in this range.

Figure 5 shows the spectral width distributions at $13 \mathrm{MHz}$ as a function of range during a special experimental campaign run on 8 July 1999 and again three days later on 11 July 1999. During this experiment, the first range gate was set to $60 \mathrm{~km}$ and the gates were separated by $15 \mathrm{~km}$. At $13 \mathrm{MHz}$, echo returns could be attributed to a small contribution from the upward looking lobe, so that meteors at different ranges from the radar could be inferred. The gain-elevation characteristics of the radar at $13 \mathrm{MHz}$ are such that the almost vertically pointing second peak has moved further away from the zenith than for the $12 \mathrm{MHz}$ trace in Fig. 1b, so a range of $110 \mathrm{~km}$ remained consistent with observations of the meteor layer. On the uncontaminated day, (Fig. 5a) the smooth fall off of meteor echoes beyond $240 \mathrm{~km}$ indicated that the furthest useful range was around $400-450 \mathrm{~km}$, which is equivalent to the seventh range gate in the common mode where the first range was $180 \mathrm{~km}$ and the resolution was $45 \mathrm{~km}$. This is an improvement on the cutoff point of $360 \mathrm{~km}$ that has been used in previous studies (e.g. Hall et al., 1997; Arnold et al., 2001). Similarly, spectral widths below $40 \mathrm{~ms}^{-1}$ were likely to be related to meteor activity.

On the 11th, the maximum count rate was around 40 occurrences per range gate per unit spectral width interval per day. Contrast this with the situation three days earlier (Fig. 5b) when there was a considerable enhancement at a (a)

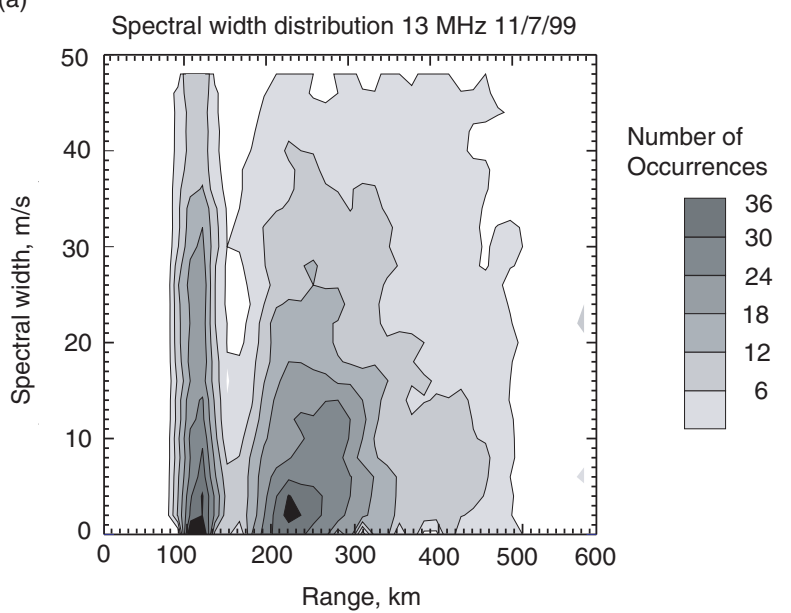

(b)

(b) Spectral width distribution $13 \mathrm{MHz}$ 8/7/99

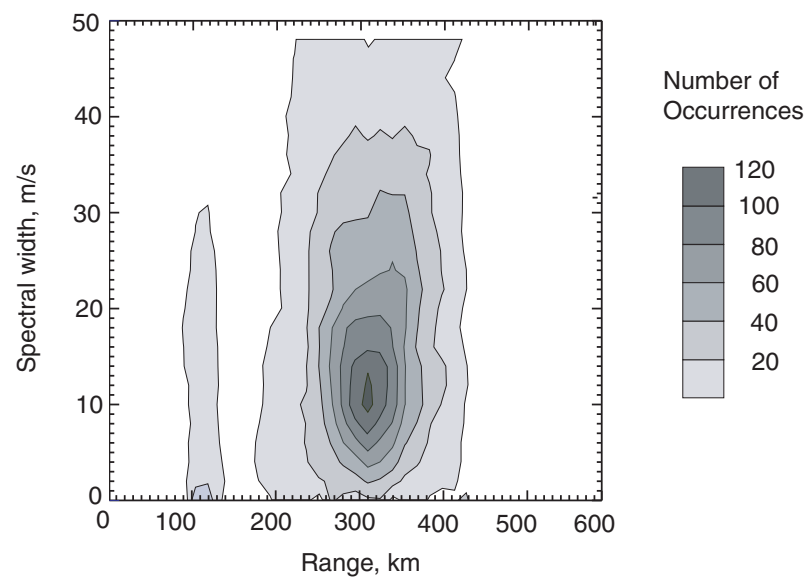

Fig. 5. Spectral width vs. range for the nearest range gates at $13 \mathrm{MHz}$ using a high resolution meteor mode for the Hankasalmi HF radar (a) 11 July 1999 (b) 8 July 1999. Note the change in scales to reflect the differing occurrence distributions on each day.

distance of $320 \mathrm{~km}$ from the radar and a peak spectral width of $12 \mathrm{~ms}^{-1}$ that overwhelmed the signal from the meteors beyond $200 \mathrm{~km}$. To accommodate this change in occurrence rates, it was necessary to rescale the contours by more than a factor of three. The 8th was not associated with any significant meteor shower activity to account for this enhancement. The contamination was confined to a relatively narrow band, as can be seen by the absence of unusual values at the closer ranges.

Any E-layer contamination within near range gates that has characteristics more closely resembling those of meteors can be detected using information from the radars' interferometers. While only a small fraction of echoes generate an unambiguous elevation angle and the measurements are subject to significant errors (Milan et al., 1997), this quantity is a useful qualitative indicator of significant E-region contributions. D-region echoes give an elevation angle consistent with a height range of $80-105 \mathrm{~km}$ (Fig. 6a), while any E-layer 


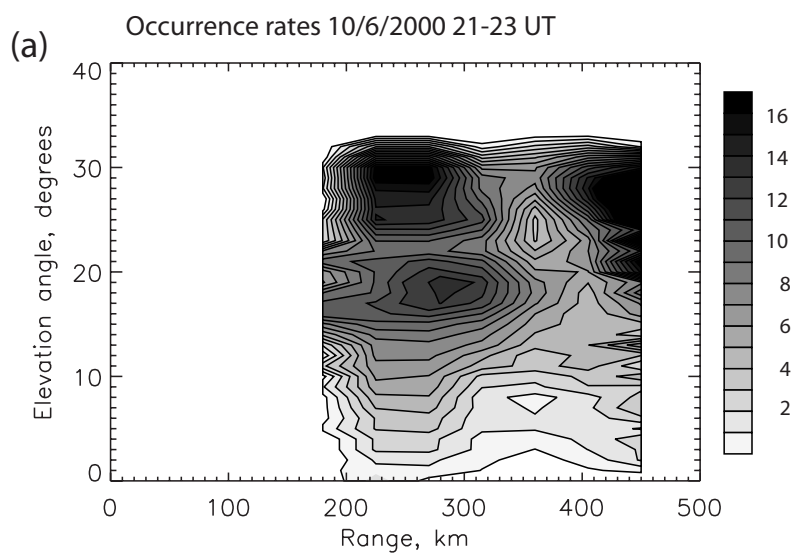

(b)

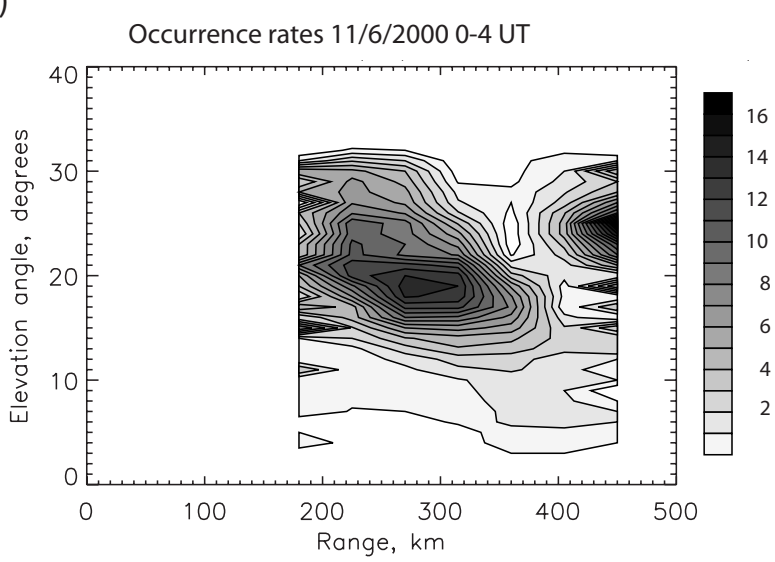

Fig. 6. Observed elevation angles, measured in degrees of near range echoes by the Hankasalmi HF radar (a) 21:00-23:00 UT, 10 June 2000 (b) 00:00-04:00 UT, 11 June 2000

echoes will produce a second distribution that corresponds to an altitude of $110 \mathrm{~km}$ or more (Fig. 6b). The technique is most useful during the summer months when the meteor count, PMSE and also the E-layer reflections are abundant.

To examine the annual cycle in the mean spectral width and whether the summer months were especially anomalous, this parameter was binned according to season and local time from the CUTLASS Finland radar at 10 and $12 \mathrm{MHz}$, for the period September 1999 to August 2000, when the first six range gates were considered together. In the months of November and March the mean spectral widths at $12 \mathrm{MHz}$ were dominated by very low value returns associated with ionospheric layer contamination. Reducing the furthest range gate to within $270 \mathrm{~km}$ removed much of this problem, but at the expense of rejecting ten months of good data at the furthest ranges and a number of satisfactory days for the bad months.

As an alternative approach anomalous data were rejected by requiring the mean spectral width to be between $16-24 \mathrm{~ms}^{-1}$ and also that the average power remained below $30 \mathrm{~dB}$, and the remaining spectral width data were to be binned as before. The resulting monthly intervals contained spectral widths that were comparable with those using the first five range gates only, indicating that the worst of the

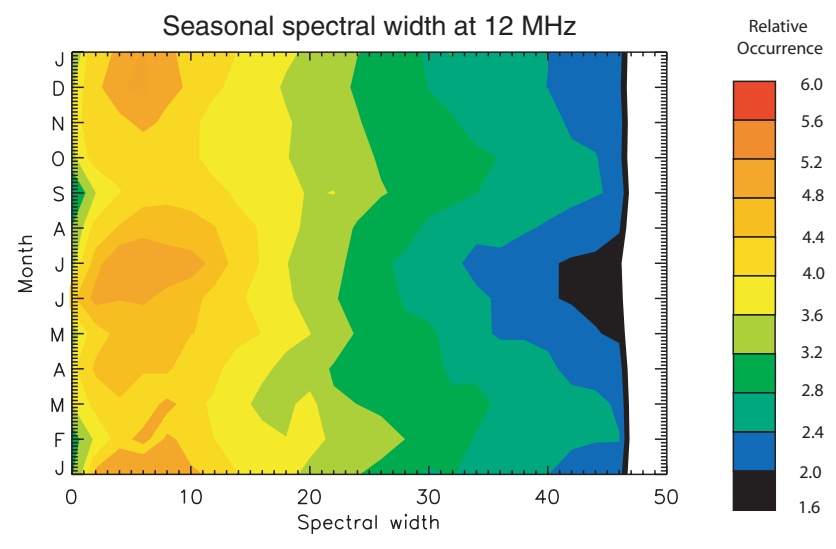

Fig. 7. Monthly averaged variation of low spectral widths with season for the Hankasalmi HF radar operating during 1999-2000 using beams $6-10$ for range gates 0 to 6 and operating at $12 \mathrm{MHz}$. Occurrence rates have been normalised for each month. (a) Raw meteor echoes (b) Meteor echoes processed for ionospheric contamination.

contamination had been successfully removed (Fig. 7). Note also a semiannual variation in the spectral width distribution that may be attributed to changes in the D-region temperature (Arnold et al., 2001).

\section{Backward lobe correction}

From Fig. 1, it was clear that the CUTLASS radars operating at $10 \mathrm{MHz}$ and to a lesser extent, at $12 \mathrm{MHz}$, would detect meteor echoes originating from "behind the radar". Any time-averaged winds would have a component along the beam that is perceived to be travelling in the opposing direction to the flow. If the meteor distribution was isotropic and the gain sensitivities between the front and back lobes were identical, then the radar would not be able to observe a net flow in either direction. Fortunately, the rear lobe signal is over $10 \mathrm{~dB}$ weaker than the front lobe, but with meteor echo strengths above $20 \mathrm{~dB}$ not uncommon, that still leaves a large number of undesirable signals.

During the summer, in the hours just after midnight, the return power of the meteors is strongest. At this time, a minimum return power threshold of $20 \mathrm{~dB}$ does not significantly affect the ratio of front to back echoes. However, during the afternoon and in the winter season, the echoes become much weaker and the population of return echoes from behind diminishes considerably. Therefore, the measured velocity was closer to the true velocity.

Use was made of the return power variation of meteor echoes as a function of local time, season and operating frequency. To obtain a data set that consisted entirely of $10 \mathrm{MHz}$ returns, 1997 was selected. During the interval 1999-2000, there were sufficient days in each month operating continuously at $12 \mathrm{MHz}$ to generate a comparable climatology.

Beams 5-10 were selected to measure the meridional winds, as these could be obtained without modifying the lineof-sight observations. The monthly mean meridional veloci- 


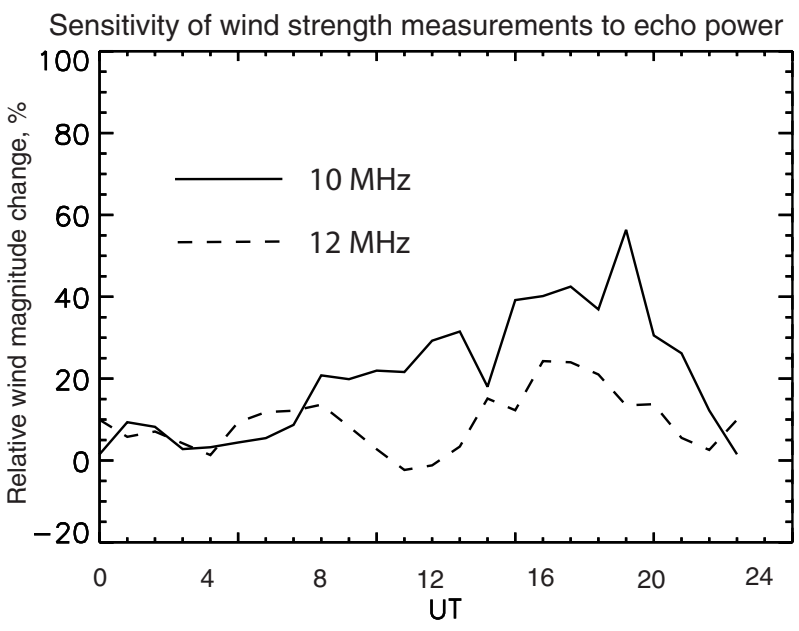

Fig. 8. Change in SuperDARN Doppler meteor wind magnitude between high power echoes ( $>20 \mathrm{~dB}$ above noise) and all echoes, expressed as a percentage of the wind magnitude for all echoes over a diurnal cycle for 10 and $12 \mathrm{MHz}$. The lines are average values for the first six range gates of the common programme.

ties for each hour of local time were determined for each of the six nearest range gates by assuming that the vertical velocity component was zero and the mean meteor altitude was $95 \mathrm{~km}$ (see, for example, Arnold et al., 2001). The procedure was repeated with a minimum power threshold of $20 \mathrm{~dB}$ applied. As the average signal strength diminished in the day-time and during the winter, so too did the probability of detecting a meteor echo from behind the radar - much more so than for the forward looking lobe. The extent of back lobe contamination of the data could be determined by comparing the relative difference in the magnitude of the meridional winds between using the high power echoes only and using all of the available data, at both 10 and $12 \mathrm{MHz}$. There was a distinct peak at 19:00 UT in the $10 \mathrm{MHz}$ case, where the amplitude of the meridional wind increased by approximately $40-50 \%$ (Fig. 8). The enhancement in the amplitude was found to be only $20 \%$ at $12 \mathrm{MHz}$, as the influence of the rear lobe was weaker.

Small increases in the frequency above $12 \mathrm{MHz}$ would bring the attenuating factor closer to zero, suggesting that $13-15 \mathrm{MHz}$ would produce purer velocity measurements. However, the number of observed meteor echoes decreases rapidly with frequency, making the determination of mean wind speeds more difficult (McKinley, 1961). Twelve MHz represents a good compromise at times when the meteor count was high and $10 \mathrm{MHz}$ would be preferable at other times.

\section{Comparison with the VHF meteor radar}

Initially, all data from the Kiruna VHF meteor radar between 88 and $104 \mathrm{~km}$ were used to derive the local time and seasonal variability of the meridional winds between Septem-
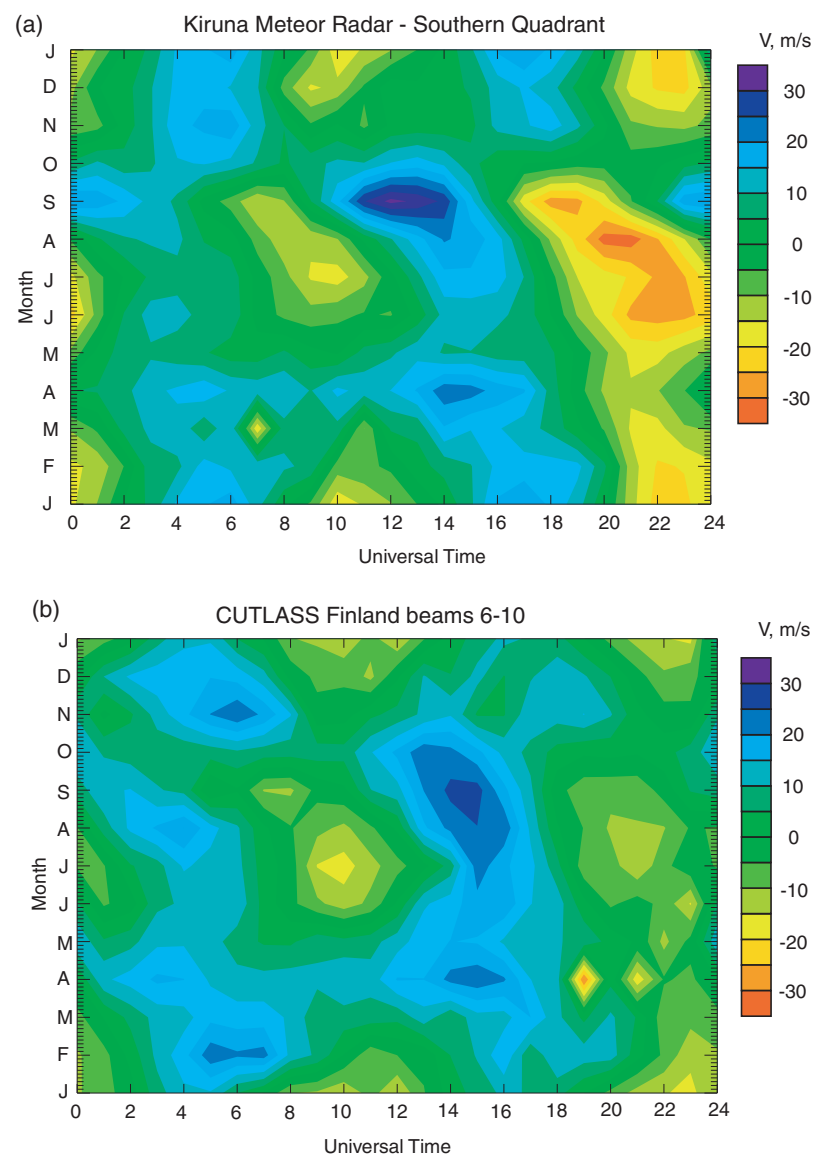

Fig. 9. Seasonal and diurnal meridional winds around $96 \mathrm{~km}$ for (a) the Esrange VHF radar southern quadrant and (b) SuperDARN Finland HF radar beams 6-10.

ber 1999 and September 2000. The radar interferometer provided an accurate determination of the elevation and azimuth of each individual meteor, which with the Doppler line-ofsight velocity then contributed to a statistical fit to obtain the best hourly zonal and meridional wind speeds. (It is assumed that the vertical velocity component is zero.) Note that the location of the meteors collected by the SuperDARN radar is determined by assuming that it is coming from a particular beam and range gate cell. Agreement with the SuperDARN Finland HF was quite good, but it was found that there were significant latitudinal variations over the VHF radar field of view. To reduce the geographical differences between the two radars, only data from between the Southeast and Southwest of Kiruna were used in the comparison (Fig. 9). The CUTLASS data were processed to reduce E-layer biases, but the rear-lobe contamination was left uncorrected. Beams six to ten of the CUTLASS radar were selected as they looked essentially northward and described a segment of 15 degrees. Only line-of-sight velocities were used, so there would be a minor contribution from the zonal wind component for the off-meridional beams. Assuming that the meteor height was fixed at $97 \mathrm{~km}$, the horizontal component of the wind at each range gate could be inferred (Arnold et al., 2001). The best 
(a)

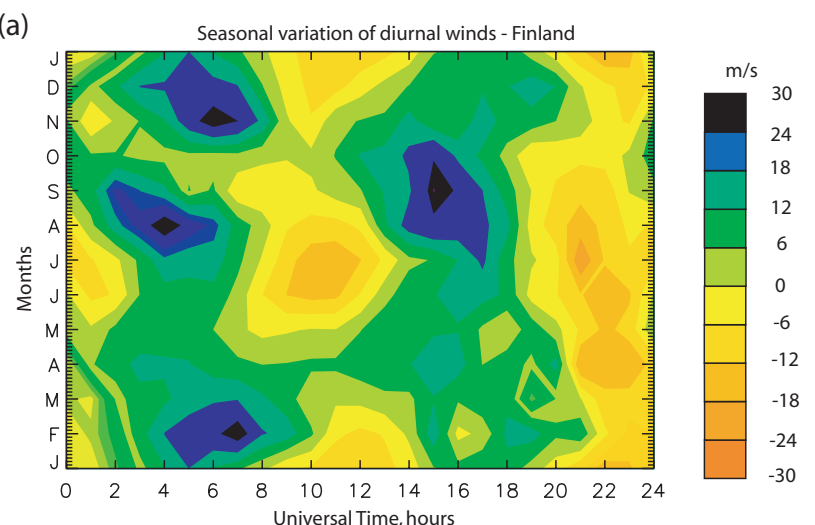

(b)

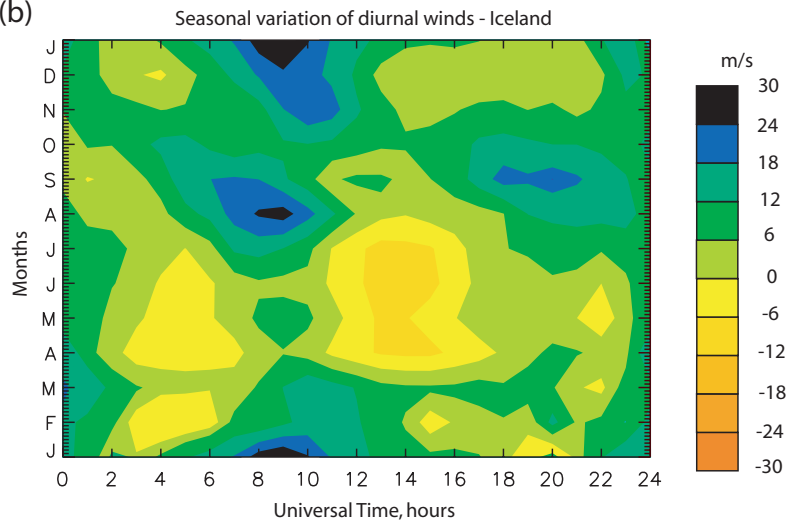

Fig. 10. Seasonal and diurnal line-of-sight horizontal winds (positive towards the north-northeast direction) for the CUTLASS pair of SuperDARN radars between January and December 1997 (a) Finland beams 10-15 (b) Iceland East beams 0-5.

agreement was between the hours of 06:00 and 18:00 UT when the radar was operating at $12 \mathrm{MHz}$ (and had a reduced backward-looking component). Agreement was qualitatively reasonable at other local times but the wind speed was lower for the HF data. The correction factor of around $50 \%$ as described in the preceding section would account for much of this difference.

The statistical variance between the Kiruna and CUTLASS radars was computed from the mean of the squares of the differences at each element of the climatological grid shown in Fig. 9 - namely for each hour of Universal Time and the month of the year. It was found to be less than that between the north and south centred quadrants of the VHF radar, suggesting that a significant fraction of the remaining discrepancy was attributable to geographical variations rather than experimental errors. Note also a few points around 19:00 UT in April in the HF data where several local maxima were located. The criterion for rejecting potentially contaminated data did not make any allowance for seasonal variability in the mean power of the meteor backscatter returns. Therefore, during the solstices, it was likely that "good" meteor days were more likely to be rejected than during the equinox. A more detailed model of meteor characteristics will take this into account in the future.

\section{Comparison between the CUTLASS Finland and CUTLASS Iceland radars}

The two radars that comprise the CUTLASS element of the SuperDARN chain are virtually identical in their construction and performance. Most of the differences between their respective wind climatologies will be due to geographical variations in either the horizontal winds, the ionospheric contamination, or to explicit changes to the operating modes of the two radars. The Iceland radar is much more likely to be located within the auroral oval than its Finland counterpart and so will experience different contamination conditions. Also, there is a three-hour lag in the minimum count rate with respect to the Finland radar as the Earth rotates around its axis. All of these factors will impinge upon the measured velocities by the radars. Data from 1997 were chosen for the comparison as both radars were operating continuously at $10 \mathrm{MHz}$ at that time. Beams $10-15$ from the Finland radar (Fig. 10a) were compared with the first six beams from Iceland (Fig. 10b) as they both look towards the north-northeast direction. There was a slight mismatch of around 10 degrees between the two swaths, but the use of six adjacent beams instead of just three provided increased data coverage.

The three-hour lag in the Iceland data set is apparent in the semi-diurnal tidal structure. The agreement was closest in the summer months before noon (local time). This is a reflection of the enhanced data quality at these times. The velocity values were most noisy during the winter afternoon where the data rates can be quite low. Applying the appropriate correction factor to compensate both radars for the backward lobe velocity reduction would bring the results into better agreement with the Esrange radar observations.

\section{Discussion and conclusions}

The SuperDARN operating frequencies of $8-20 \mathrm{MHz}$ (primarily $10-12 \mathrm{MHz}$ ) present a challenge for making quantitative observations of meteor winds in the upper mesosphere and lower thermosphere. However, the geographical and temporal extent of the network provides a unique opportunity to generate an important and new data base of winds in this region. Twelve $\mathrm{MHz}$ is a good choice of frequency for meteor observations in that the count rate is acceptably high and the contamination relatively low. Ten $\mathrm{MHz}$ produces more meteors at the expense of a broadening of the beam pattern, enhanced rear lobe distortion of the measurements and its susceptibility to ionospheric influences. The eastern flank of the Northern Hemisphere chain, namely the CUTLASS radars have used $10 \mathrm{MHz}$ for its common programme mode for much of the past five years and will continue to do so for the foreseeable future.

Several earlier studies confined the definition of meteors to those signals that have spectral widths less than $20 \mathrm{~ms}^{-1}$. Our work has suggested that there is continuity at least up to $40 \mathrm{~ms}^{-1}$ and possibly beyond. While the possibility of contamination increases with spectral width, even the lower 
threshold was not totally effective at screening out unwanted signals, so the introduction of algorithms to identify contaminants within this range allowed for more data of better quality to be considered. Large patches with strong echo powers, typically associated with sporadic-E layers will have a tendency to bias the wind observations to greater altitudes. However, the spatial and temporal coherence of these echoes makes it relatively straightforward to remove them from the data set. To date, we have employed relatively crude hourly mean statistics to identify unsatisfactory intervals where the possibility of contamination is high. There is room for more sophisticated algorithms that divide the field-of-view into smaller temporal and spatial segments.

Another possible source of targets in the upper mesosphere/lower thermosphere region arises from the ability of the SuperDARN radars to detect Polar Mesospheric Summer Echoes (PMSEs). Peak activity levels occur at altitudes between $80-90 \mathrm{~km}$, between the months of June and August in the Northern Hemisphere (see, for example, Kelley et al., 2002). In contrast to the sporadic-E echoes, PMSE layers are around $10 \mathrm{~km}$ lower than would be typical of the meteor layer. While the interferometer used by the SuperDARN radars is relatively crude, it can often be used to help to distinguish between the two populations, especially when the radar is operating at a range resolution of $15 \mathrm{~km}$. Also, the diurnal variation of meteor rates is well established, so unusually dense populations of echoes with relatively uniform spectral widths and velocities in the summer months during non-meteor shower intervals would indicate that a PMSE cloud may be present. Additional filters could check for such echoes and isolate them. Indeed, PMSEs make excellent targets for monitoring line-of-sight velocities when they are present, and this will be the subject of a future study.

At $10 \mathrm{MHz}$, and to a lesser extent 12 , there was a significant contribution to the wind climatologies from meteors detected behind the radar. These could reduce the measured velocity by up to $50 \%$, so a correction factor that depends on operating frequency will need to be applied when using the SuperDARN radars. The introduction of dual transmission pulse capability on CUTLASS should provide a means to use this effect to our advantage. Two signals with distinctive frequencies will be sent out with a temporal separation of just $400 \mu \mathrm{s}$, to illuminate the same volume of space. For all but the briefest meteor echoes, this should ensure that coincident observations in the two channels occur. The ratio of back scattered power returns from the two pulses reflecting from the same target will be markedly different, depending on whether the signal came from the front or the back of the radar. Explicit observations of rear lobe echoes, in combination with the VHF meteor data, would extend the latitudinal coverage of wind measurements by the two instruments to $1500 \mathrm{~km}$.

The CUTLASS HF radars observed neutral winds that were comparable to a dedicated VHF meteor radar system deployed approximately $700 \mathrm{~km}$ away. Being relatively more powerful and operating at a significantly lower frequency, the HF radars picked up considerably more echoes per unit area, thereby compensating for their relatively narrow fieldsof-view. For the purposes of this paper, we have developed long-term climatological data sets where most of the remaining contamination was uncorrelated to the neutral wind signal and so may be discounted as noise. Differences between the Iceland and Finland winds confirmed that operating frequency and local ionospheric conditions needed to be considered carefully in the creation of D-region winds around the SuperDARN network. Once this has been done, the data will be of great value in the study of the dynamics of the upper mesosphere and the lower thermosphere.

Acknowledgements. The authors wish to thank the team at the Radio and Space Plasma Physics group who constructed, deployed and operated the CUTLASS HF radars over the past five years. We are grateful for the constructive comments of one of the referees. N. F. Arnold was supported by an advanced fellowship from the UK Particle Physics and Astronomy Research Council, P.A. Cook by PPARC grant RP16017 and CUTLASS operations were supported by PPARC grant RP16021.

The Editor in Chief thanks C. Meek for his help in evaluating this paper.

\section{References}

Arnold, N. F. and Robinson, T. R.: Solar cycle changes to planetary wave propagation and their influence on the middle atmosphere circulation, Ann. Geophysicae, 16, 69-76, 1998.

Arnold, N. F. and Robinson, T. R.: Amplification of the influence of solar flux variations on the middle atmosphere by planetary waves, Space Sci. Rev., 94, 279-286, 2000.

Arnold, N. F., Robinson, T. R., Lester, M., Byrne, P. B., and Chapman, P. J.: Super Dual Auroral Radar Network observations of fluctuations in the spectral distribution of near range meteor echoes in the upper mesosphere and lower thermosphere, Ann. Geophysicae, 19, 425-434, 2001.

Fels, S. B., Mahlmann, J. D., Schwarzkopf, M. D., and Sinclair, R. W.: Stratospheric sensitivity to perturbations in ozone and carbon dioxide: radiative and dynamical response, J. Atmos. Sci., 37, 2265-2297, 1980.

Fleming, E. L., Chandra, S., Burrage, M. D., Skinner, W. R., Hays, P. B., Solheim, B. H., and Sheppard, G. G.: Climatological mean wind observations from the UARS high-resolution Doppler imager and wind imaging interferometer: comparison with current reference models, J. Geophys. Res., 101, 10 455-10 476, 1996.

Gray, L. J., Blackburn, M., Chipperfield, M. P., Haigh, J. D., Jackson, D. R., Shine, K. P., Thuburn, J., and Zhong, W.: First results from a 3-D model of the middle atmosphere, Adv. Space Res., 13, 363-372, 1992.

Greenhow, J. S.: Characteristics of radio echoes from meteor trails, Proc. Phys. Soc. London, 65B, 169-174, 1952.

Greenhow, J. S. and Neufeld, E. L.: The diffusion of ionized meteor trails in the upper atmosphere, J. Atmos. Terr. Phys., 6, 133-140, 1955.

Greenwald, R. A., Baker, K. B., Dudeney, J. R., Pinnock, M., Jones, T. B., Thomas, E. C., Villain, J.-P., Cerisier, J.-C., Senior, C., Hanuise, C., Hunsucker, R. D., Sofko, G., Koehler, J., Nielsen, E., Pellinen, R., Walker, A. D. M., Sato, N., and Yamagishi, J.: DARN/SuperDARN: A global view of the dynamics of high latitude convection, Space Sci. Rev., 71, 761-796, 1995. 
Hall, G. E., MacDougall, J. W., Moorcroft, D. R., and St.-Maurice, J.-P.: Super Dual Auroral Network observations of meteor echoes, J. Geophys. Res., 102, 14 603-14 614, 1997.

Hocking, W. K.: Temperatures using radar-meteor decay times, Geophys. Res. Lett., 26, 3297-3300, 1999.

Hocking, W. K., Thayaparan, T., and Jones, J.: Meteor decay times and their use in determining a diagnostic mesospheric pressure parameter: methodology and one year of data, Geophys. Res. Lett., 24, 2977-2980, 1997.

Hussey, G. C., Meek, C. E., André, D., Manson, A. H., Sofko, G. J., and Hall, C. M.: A comparison of Northern Hemisphere winds using SuperDARN meteor trail and MF radar wind measurements, J. Geophys. Res., 105, 18 053-18 066, 2000.

Kelley, M. C., Huaman, M., Chen, C. Y., Ramos, C., Djuth, F., and Kennedy, E.: Polar mesosphere summer echo observations at HF frequencies using the HAARP Gakona Ionospheric Observatory, Geophys. Res. Lett., 29, 12, 10.1029/2001GL013411, 2002.

Kopp, E.: On the abundance of metal ions in the lower ionosphere, J. Geophys. Res., 102, 9667-9674, 1997.

McLandress, C., Shepperd, G. G., Solheim, B. H., Burrage, M. D., Hays, P. B., and Skinner, W. R.: Combined mesosphere/thermosphere winds using WINDII and HRDI data from the Upper Atmosphere Research Satellite, J. Geophys. Res., 101, 10 441-10 454, 1996.

McKinley, D. W. R.: Meteor science and engineering, McGrawHill, New York, 1961.
Milan, S. E., Jones, T. B., Robinson, T. R., Thomas, E. C., and Yeoman, T. K.: Interferometric evidence for the observation of ground backscatter originating behind the CUTLASS coherent HF radar, Ann. Geophysicae, 15, 29-39, 1997.

Ogawa, T., Nishitani, N., Sato, N., Yamagishi, H., and Yukimatu, A. S.: Upper mesosphere summer echoes detected with the Antarctic Syowa HF radar, Geophys. Res. Lett., 29, 7, 10.1029/2001GL014094, 2002.

Peixoto, J. P. and Oort, A. H.: Physics of climate, American Institute of Physics, pp. 520, 1992.

Rees, M. H.: Physics and chemistry of the upper atmosphere, Cambridge University Press, pp. 289, 1989.

Robertson, D. S., Lilly, D. J., and Elford, W. G.: Measurements of winds in the upper atmosphere by means of drifting meteor trails I, J. Atmos. Terr. Phys., 4, 255-274, 1953.

Röttger, J. and Vincent, R. A.: Observations of the middle atmosphere and lower thermosphere by radars, in: The Upper atmosphere: data analysis and interpretation, edited by Dieminger, W., Hartmann, G. K., and Leitinger, R., 327-369, 1996.

Smith, E. K.: Temperate zone sporadic-E maps ( $f o$ Es $>7 \mathrm{MHz}$ ), Radio Science, 13, 571-582, 1978.

Weber, E. J., Whalen, J. A., Wagner, R. A., and Buchau, J.: A 12 hour case study of auroral phenomena in the midnight sector: electrojet and precipitating particle characteristics, J. Geophys. Res., 88, 7155-7171, 1977. 